\title{
Pensando a educação ambiental sob o enfoque didático de natureza socioconstrutivista: contribuições do Projeto Acre 2000 de Educação Ambiental
}

\author{
Carla Gracioto Panzeri ${ }^{1}$ \\ Maurício Compiani ${ }^{2}$ \\ Laerte Alberto Junior ${ }^{3}$
}

Resumo: Este trabalho aborda a relevância do enfoque didático de natureza socioconstrutivista na formação continuada de professores em educação ambiental. Nesse sentido, restringimos nossas discussões aos princípios socioconstrutivistas norteadores das práticas formativas realizadas no âmbito do Projeto Acre 2000 de Educação Ambiental, a saber: a) articulação entre conhecimentos cotidianos e científicos na construção do conhecimento escolar, b) zona de desenvolvimento proximal e a prática docente e c) construção de conceitos à luz da mediação dialógica. Afirmamos que os resultados da adoção desse enfoque na formação de professores em educação ambiental foram: o acesso às ideias que os envolvidos no processo formativo possuíam sobre as questões ambientais enfocadas, o estabelecimento de um processo dialógico entre os diversos conhecimentos que os indivíduos possuíam sobre as questões e entre esses conhecimentos e aqueles produzidos pela ciência e a possível conexão entre o processo dialógico externo e o diálogo interno, no que diz respeito à construção de conceitos.

${ }^{1}$ Doutora em Ensino e História de Ciências da Terra, Dep. de Geociências Aplicadas ao Ensino, Universidade Estadual de Campinas (Unicamp). Contato: Rua Fernão Lopes, no 1400, bloco 03, apart. 212, Parque Taquaral, Campinas, SP - CEP 13087-051. E-mail: panzeri@ige.unicamp.br.

2 Doutor em Educação, professor associado - livre-docente, Dep. de Geociências Aplicadas ao Ensino, Instituto de Geociências, Universidade Estadual de Campinas (Unicamp). E-mail: compiani@ige.unicamp.br

3 Bacharel em Sociologia, Pontifícia Universidade Católica de São Paulo, docente da E.E. Adalberto Nascimento, Campinas, SP. E-mail: laerteajunior@ig.com.br 
Palavras-chave: Socioconstrutivismo. Formação continuada. Temática ambiental.

Abstract: This paper discusses the relevance of a social constructivist teaching approach in teacher continuing education in environmental education. In this regard, we restrict our discussions to the constructivist principles that guide the training practices carried out under the 2000 Acre Environmental Education Project, namely: a) relationship between spontaneous and scientific knowledge in the construction of school knowledge, b) zone of proximal development and teaching practice, and c) construction of concepts in light of dialogic mediation. We affirm that the results of adopting this approach in teacher training in environmental education are: access to the ideas that those involved in the training had on the discussed environmental issues, the establishment of a dialogic process among the variety of knowledge that individuals had about the issues and between that knowledge and science-based knowledge, and the possible connection between the external dialogic process and internal dialogue, regarding the construction of concepts.

Keywords: Social constructivism. Continuing education. Environmental theme.

\section{Introdução}

Neste trabalho apresentamos um recorte da pesquisa de mestrado intitulada "Educação Ambiental e Itinerários Curriculares no Cotidiano das Séries Iniciais do Ensino Fundamental: contribuições teórico-metodológicas do Projeto Acre 2000 de Educação Ambiental, Rio Branco/AC”, defendida em março de 2006 no Instituto de Geociências, Unicamp. Cabe ressaltar que este recorte foi realizado para possibilitar o aprofundamento das discussões acerca dos possíveis entrelaçamentos da adoção de abordagens de natureza socioconstrutivista $^{4}$ com a educação ambiental.

4 Usamos "socioconstrutivista" por nos embasarmos na abordagem sóciohistórica de Vygotsky. Além disso, usamos "abordagem de natureza” porque, segundo Compiani et al. (1999), apoiados nas ideias de Coll, não há uma metodologia didática socioconstrutivista, mas uma didática geral de natureza 
O fato de existir uma ampla diversidade de noções e práticas em educação ambiental, categorizadas pela bibliografia da área em pelo menos 15 diferentes correntes (SAUVÉ, 2005), enfatiza a necessidade de esclarecimento sobre nossa abordagem, que teve em vista a formação de professores e alunos com uma postura crítica diante das questões ambientais emergentes na localidade.

Assim, por meio da sistematização dos conhecimentos produzidos no cotidiano do Projeto Acre 2000 de Educação Ambiental, identificamos as contribuições deste para processos de formação em educação ambiental, voltados para professores das séries iniciais do ensino fundamental.

Durante o desenvolvimento do referido projeto, utilizamos a observação participativa, as entrevistas semiestruturadas, o registro em cadernetas de campo, a escuta sensível, o relato de vida, as entrevistas de grupo e a análise documental.

No que diz respeito à pesquisa, acreditamos numa análise processual, segundo a qual os princípios metodológicos e valores que nortearam a formação das multiplicadoras ${ }^{5}$ influenciaram o modo como elas mediaram a formação dos professores e o modo como estes passaram a se relacionar e trabalhar com seus alunos.

Utilizou-se o sistema de combinação de fontes múltiplas de dados de investigação por diversos procedimentos, denominado triangulação. Entendemos triangulação como "uma maneira de olhar as coisas por ângulos diferentes, ou seja, usando uma variedade de fontes, métodos ou membros do grupo de trabalho para coletar os mesmos dados" (DIETZ; TAMAIO, 2000).

Discutimos neste artigo, especificamente, o processo de adoção de abordagens socioconstrutivistas por parte dos docentes participantes de projeto de formação continuada em educação ambiental. Tais discussões e reflexões tornaram-se possíveis devido ao registro e à sistematização seguindo a abordagem metodológica da pesquisa-ação utilizada ao longo do projeto.

socioconstrutivista.

5 Usamos o feminino no caso de "multiplicadoras" porque só havia docentes do gênero feminino nessa função. 
No que diz respeito ao recorte delineado enquanto foco deste artigo, afirmamos que buscamos, por meio da análise dos registros da observação participante e das entrevistas realizadas com docentes participantes do Projeto Acre 2000 de Educação Ambiental, identificar e refletir sobre as práticas com enfoque didático de natureza socioconstrutivista adotadas pelas multiplicadoras e professores.

Apresentamos a seguir algumas informações a respeito do referido projeto a fim de contextualizarmos a pesquisa, o que, a nosso ver, é fundamental à compreensão desse processo, e depois passamos para o foco do artigo.

\section{O Projeto Acre 2000 de Educação Ambiental}

A formação continuada de professores em exercício em educação ambiental foi desenvolvida enquanto um dos componentes do Projeto Acre 2000 de Educação Ambiental, realizado no período de 2000 a 2004 (PANZERI, 2006, 2007; PANZERI; COMPIANI, 2003, 2006) e coordenado pela Associação S.O.S. Amazônia, em parceria com as secretarias de Educação dos municípios de Rio Branco, Cruzeiro do Sul, Mâncio Lima e Rodrigues Alves/AC e com o apoio do Fundo Mundial para a Natureza (WWF - Brasil). Participaram desse projeto professores das séries iniciais do ensino fundamental da rede pública dos municípios citados acima.

O cotidiano do processo de formação continuada constituiu-se essencialmente na elaboração coletiva de unidades didáticas ${ }^{6}$, o que foi feito seguindo-se estas orientações gerais: i) apresentar foco temático nas questões ambientais locais; ii) apresentar integração/encadeamento entre as atividades elaboradas; iii) propor a ruptura da estrutura disciplinar por meio da adoção de temas ambientais locais como organizadores dos itinerários curriculares.

Apoiados na ideia de que a educação tem um papel político, tomamos como finalidade da elaboração e execução desse projeto a participação das escolas da rede pública acreana nas discussões acerca das questões ambientais locais, referentes à implantação de unidades de

${ }^{6}$ Unidades didáticas $=$ planejamento didático para determinado período do ano letivo 
conservação, ao tratamento inadequado dos resíduos sólidos, à poluição dos corpos d' água, à supressão da Floresta Amazônica e à perda da biodiversidade, entre outras.

Essa ideia foi determinante na escolha dos municípios participantes do projeto, e três deles (Mâncio Lima, Rodrigues Alves e Cruzeiro do Sul) foram priorizados devido ao fato de parte de seus territórios abrigar o Parque Nacional da Serra do Divisor, importante unidade de conservação localizada no extremo oeste do Estado do Acre. A escolha de Rio Branco decorreu do fato de ser a capital e apresentar a maior concentração populacional do Estado, constituindose em importante centro de formação da opinião pública.

Partindo do pressuposto de que educação ambiental é, antes de tudo, educação, buscamos na interface com esta o enfoque didático que melhor "conversasse" com nossa concepção de educação ambiental crítica e dialógica. Assim, para desenvolver a formação em educação ambiental nessas localidades, o projeto tomou o socioconstrutivismo como abordagem metodológica, uma vez que considerávamos o caráter processual e inacabado do conhecimento (GARCIA; CANO, 2006). Essa noção se opõe à de que há um conhecimento pronto, a ser "descoberto" pelos professores/multiplicadoras, no caso de um processo de formação continuada, e pelos estudantes, no caso do desenvolvimento na unidade didática em sala de aula.

Portanto, optamos pelo socioconstrutivismo por acreditarmos que suas premissas eram as mais consequentes com a finalidade de formar professores ${ }^{7}$ emancipados que abordassem as questões ambientais acreanas de modo imbricado às disciplinas clássicas trabalhadas nas séries iniciais do ensino fundamental.

Em colaboração com os professores da rede pública acreana, buscamos percorrer caminhos que nos levassem a uma concepção

\footnotetext{
7 Usaremos "professor" e "professores" quando estivermos nos referindo aos mesmos de modo generalizante porque estiveram envolvidos no projeto docentes de ambos os sexos e na língua portuguesa o gênero masculino é generalizante. Contudo, ao tratarmos de uma "professora" específica, usaremos o feminino para indicar o gênero da mesma (ex.. P1 e P2).
} 
diferenciada de "conhecimento escolar", a qual preconizasse o planejamento coletivo visando à superação da disciplinarização e à negociação de conceitos/significados/valores enquanto formas de reconhecimento da relatividade do conhecimento.

Desse modo, o Projeto Acre 2000 de Educação Ambiental inseriu-se no mapa das "múltiplas educações ambientais" enquanto iniciativa que objetivou formar professores críticos e autônomos que trabalhassem as questões ambientais integradas às atividades de sala de aula. É importante destacar que fomos influenciados pelas concepções vygotskyanas de "zona de desenvolvimento proximal", "conhecimentos cotidianos" e "interação social". Segundo Vygotsky (2000a), a "zona de desenvolvimento proximal" refere-se à:

distância entre o nível de desenvolvimento real, que se costuma determinar através da solução independente de problemas, e o nível de desenvolvimento potencial, determinado através da solução de problemas sob a orientação de um adulto ou em colaboração com companheiros mais capazes (VYGOTSKY, 2000a, p. 112).

No que diz respeito à ideia de “interação social", Pino (1993) explica que:

na perspectiva sócio-histórica a interação social é sinônimo de intersubjetividade, forma específica da sociedade e lugar de constituição do sujeito enquanto significante do ser semiótico do homem. [...] A interação social é a condição permanente de existência do sujeito, a qual se concretiza numa constante relação com os outros (PINO, 1993, p. 51).

Van Der Veer (2001) expõe as ideias de Vygotsky a respeito dos "conhecimentos cotidianos" ao afirmar: 
Por conceitos espontâneos, ele referia-se a conceitos que são adquiridos pela criança fora do contexto da instrução explícita. Em si próprios, esses conceitos são derivados basicamente dos adultos, mas nunca foram apresentados para a criança de uma maneira sistemática e não foi feita nenhuma tentativa de ligá-los a outros conceitos relacionados. Como Vygotsky reconhecia expressamente o papel dos adultos na formação desses chamados conceitos espontâneos, ele preferia chamá-los de conceitos "cotidianos", evitando, assim, a ideia de que eles houvessem sido inventados espontaneamente pela criança (VAN DER VEER, 2001, p. 295).

Retomando o projeto, afirmamos que o mesmo foi concebido priorizando a estratégia de multiplicação, em outras palavras, professores da própria rede pública acreana atuando como formadores dos seus pares. Assim, construiu-se o curso de formação continuada de professores em colaboração com as multiplicadoras do projeto, num exercício de aprender a ensinar ensinando e por meio da elaboração e desenvolvimento das unidades didáticas em sala de aula.

$\mathrm{Na}$ prática, isso se deu a partir da reflexão na e sobre a ação (SCHÖN, 1995), no caso, a aplicação da unidade didática e as reuniões de socialização, quando os professores, após terem desenvolvido atividades com seus alunos, compartilhavam com os demais professores participantes do projeto detalhes da experiência vivenciada. Durante esse processo de interação do professor que socializava sua prática com os que ouviam seu relato, instaurou-se "um" compartilhar e refletir sobre detalhes da prática pedagógica, tais como a condução da aula e a organização dos turnos de falas, entre outros.

Em relação ao projeto, vamos tratar aqui de dois momentos do processo de formação continuada: primeiramente, a formação das multiplicadoras (07 professoras) e depois a atuação destas durante a primeira aplicação do curso de formação continuada para outros professores da rede pública acreana dos municípios envolvidos.

A formação das multiplicadoras foi realizada durante o período de março de 2001 a janeiro de 2002 por duas coordenadoras do projeto e um assessor oriundo de instituição de ensino superior (Universidade Estadual de Campinas - Unicamp). Para tanto, foram realizados 41 
encontros, totalizando uma carga horária de 156 horas, incluindo-se o período de planejamento da multiplicação, ou seja, a aplicação da metodologia para as próximas turmas.

Em 2002, as multiplicadoras realizaram a primeira aplicação da metodologia do Curso de Formação Continuada em Educação Ambiental para 23 professores que trabalhavam nas séries inicias do ensino fundamental, oriundos de 4 escolas acreanas. Foram realizados 21 encontros no período de abril a outubro de 2002, o que totalizou uma carga horária de 74 horas. Durante os anos de 2003 e 2004, foram realizadas as formações de novas turmas de professores, mas esses momentos não serão abordados neste trabalho.

\section{As abordagens socioconstrutivistas}

Um dos resultados desta pesquisa foi a identificação dos princípios socioconstrutivistas (VYGOTSKY, 2000a, 2000b) que iluminaram o desenvolvimento do processo de formação continuada de professores em educação ambiental, realizado no referido projeto.

Verificou-se que o enfoque socioconstrutivista manifestou-se em três momentos desse processo: i) quando se configurou enquanto postura metodológica dos formadores, durante a formação das multiplicadoras; ii) quando as multiplicadoras desenvolveram abordagens socioconstrutivistas na condução da formação dos professores e iii) como metodologia de ensino utilizada pelos professores formados, pois se apresentava como anseio desse processo de formação a prática de uma estratégia didática geral de natureza socioconstrutivista para o desenvolvimento da educação ambiental formal.

É interessante destacar que esse anseio deriva da adoção do socioconstrutivismo enquanto abordagem metodológica do processo formativo, o qual compreende desde a formação das multiplicadoras, passando pela formação dos professores, até a ação destes para com seus alunos, em sala de aula.

Assim, além de ter apreendido a materialização de alguns princípios socioconstrutivistas, a pesquisa identificou possíveis contribuições para a utilização dos mesmos em iniciativas de educação ambiental, a saber: 

A. Articulação entre conhecimentos cotidianos e científicos na construção do conhecimento escolar;
B. Zona de desenvolvimento proximal e a prática docente;
C. Construção de conceitos à luz da mediação dialógica.

\section{A. Articulação entre conhecimentos cotidianos e científicos na construção do conhecimento escolar}

Verificou-se que o Projeto Acre 2000 de EA criou, entre os professores, a atenção para um ambiente cultural escolar de aprender a observar e de aprender com as comunidades, incorporando os recursos culturais que os alunos traziam para a escola.

Durante o processo formativo procurou-se valorizar esses aspectos, principalmente quando da realização dos trabalhos de campo e estudos do meio, enquanto abordagem possibilitadora de uma reinterpretação das condições de vida da comunidade e problematização da realidade local por meio da observação e representação focadas nos temas estruturantes.

Ou seja, não se trata de deixar de trabalhar este ou aquele conteúdo apresentado nas propostas curriculares oficiais, e sim de deslocar o foco da ação educativa por meio de alterações nos itinerários curriculares tradicionalmente percorridos pelos docentes, cujo "rumo" era ditado por especialistas, editoras de livros didáticos e políticas públicas frequentemente descoladas da realidade local, que, no caso do Estado do Acre e da Amazônia como um todo, é muito rica e particular.

O enfrentamento dessa situação pelo projeto decorreu do fato de compartilharmos das ideias de Vygotsky no que diz respeito à noção de que o conhecimento escolar emerge do movimento de interação dos conhecimentos científicos, historicamente construídos, com os conhecimentos cotidianos, impregnados de experiência pessoal e vivência. Nesse sentido, Moll, embasado nas ideias de Vygotsky, aponta que: 
Os conceitos do dia-a-dia fornecem ao desenvolvimento dos conceitos científicos o "conhecimento vivido", isto é, os conceitos do dia-a-dia medeiam a aquisição dos conceitos científicos. Em contrapartida, segundo Vygotsky, os conceitos cotidianos são dependentes, mediados e transformados por conceitos científicos (MOLL, 1996, p. 11).

Porém, percebe-se que, de modo geral, durante a escolarização são poucas as oportunidades para os alunos expressarem seus conhecimentos cotidianos, e quando isso ocorre raramente é para articulá-los com conhecimentos científicos.

Durante o processo de ensino-aprendizado é preciso considerar que os conhecimentos científicos não são adquiridos imediatamente após a leitura de um texto ou uma discussão sobre determinado conceito em sala de aula, por exemplo. Esse é apenas o início do processo de apropriação do conhecimento sistematizado pelos alunos, processo que passa necessariamente pela articulação entre científico e cotidiano.

Destaca-se, neste momento, a noção de zona de desenvolvimento proximal como uma importante estratégia docente para mapear tanto os conhecimentos oriundos da cultura local na qual os alunos estão inseridos quanto os conhecimentos científicos referentes a determinada temática. No projeto, o mapeamento da zona de desenvolvimento proximal foi realizado pelos professores com o intuito de subsidiar o planejamento de atividades que promovessem a articulação entre essas formas de conhecimento, facilitando a construção do conhecimento escolar regionalizado.

Um exemplo desse processo pode ser observado quando do trabalho com o tema água, profundamente escolarizado e para o qual existem inúmeras propostas clássicas de abordagem, em que a professora $\mathrm{P}^{8}{ }^{8}$ tomou como foco de sua ação o Igarapé São Francisco 9 .

8 P1 - Representa professora participante do projeto, cujos dados foram trabalhados durante mestrado.

9 O Igarapé São Francisco é um dos principais cursos d'água da cidade de Rio Branco. 
Nesse sentido, o foco do processo de ensino-aprendizagem não está no fato de a água ser um aspecto abiótico, mas no fato de o Igarapé São Francisco ser o corpo d'água que passa nos fundos da escola e ao lado das casas de boa parte dos alunos e que, devido a um padrão de ocupação do solo na região, historicamente construído e culturalmente consolidado, recebe o esgoto sem tratamento de todas as habitações e comércios da região.

Portanto, o foco do itinerário curricular foi deslocado dos conteúdos encontrados na proposta da Secretaria de Educação para um elemento da paisagem envolvido em inúmeros problemas ambientais que atingem e incomodam os alunos e a professora. Além disso, esse elemento constitui parte da história e da cultura da população do município.

Essa mudança na organização do itinerário curricular fica evidente ao observarmos o mapa conceitual elaborado inicialmente pelas professoras $^{10}$ (fig.1) e o mapa conceitual elaborado após a realização do trabalho de campo e reorganização da unidade didática ${ }^{11}$ (fig.2).

Verificamos que os trabalhos de campo contribuíram para o tratamento contextualizado focado nas questões ambientais emergentes na localidade. O campo, nesse caso, configurou-se enquanto o local propício à interação, em múltiplos sentidos, uma vez que durante o mesmo os alunos interagiram uns com os outros, observaram e interagiram com o meio e interagiram com a professora, questionandoa sobre o que viam e refletiam e respondendo às perguntas da mesma.

Desse modo, o campo colaborou para o tratamento contextualizado do tema "água" ao levar o aluno a observar diferentes características do Igarapé São Francisco em diferentes pontos ao longo do perímetro urbano de Rio Branco e ao propiciar a interação com esse igarapé e a população do entorno, bem como ao levar os alunos a refletirem sobre as condições desse corpo d'água, a sua conservação nesses diferentes pontos, o uso de suas águas, entre outras questões.

10 Elaborado pelo grupo de professoras do qual a professora P1 participava.

11 Elaborado pela professora P1 após a aplicação da unidade didática. 


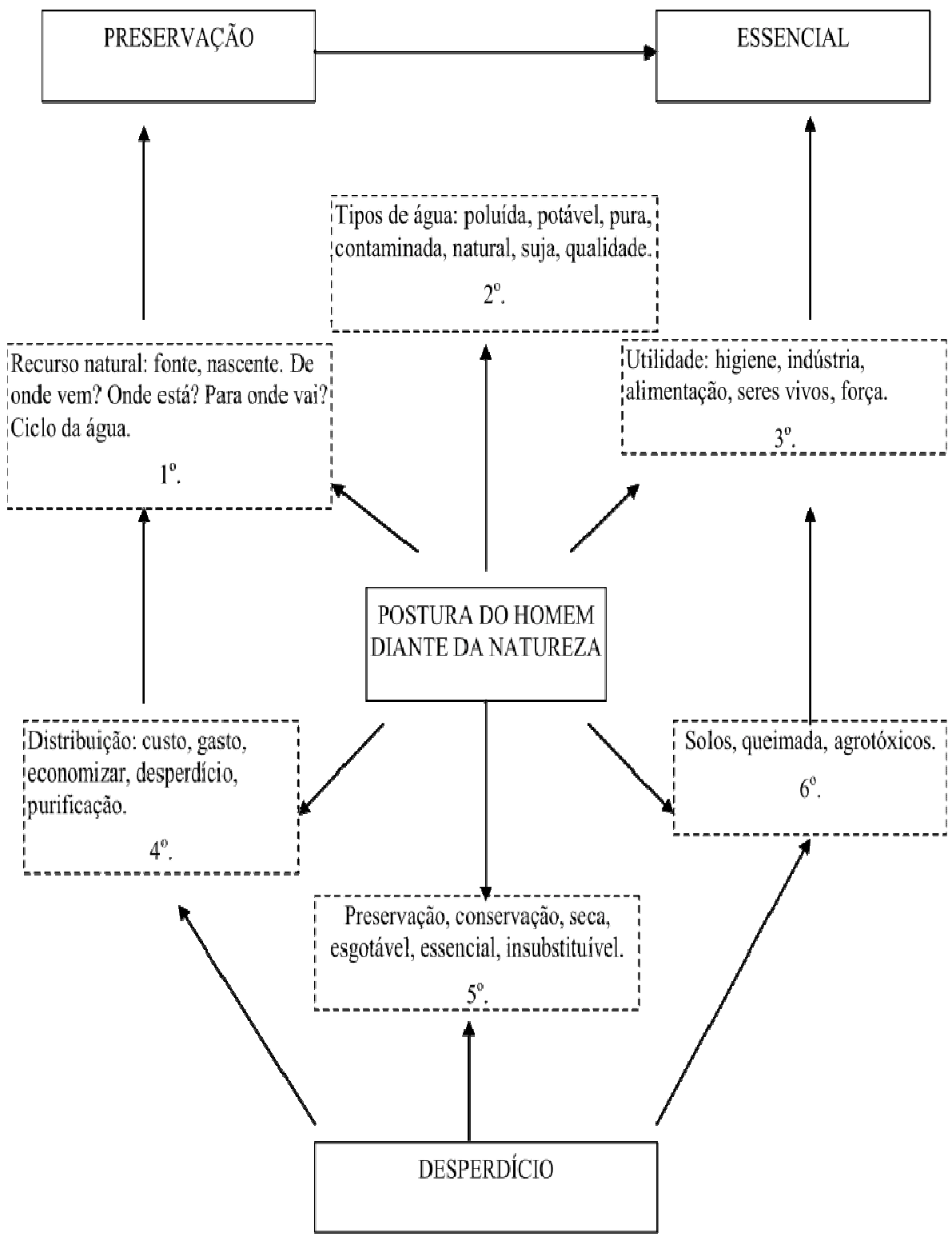

Figura 1. Mapa conceitual elaborado no início do processo formativo pela professora P1 e o grupo de professores do qual fazia parte 
A visita e a discussão de problemas reais do igarapé no entorno da escola modificaram completamente a representação sobre o meio ambiente do aluno e suas relações com o tema água, tão discutido na escola. O projeto, ao tratar o papel do conhecimento situado, traz algo de novo para o aluno compreender a água e suas relações com o meio ambiente. Na figura 1, há sentidos repetidamente tratados ao longo do percurso escolar e mesmo na mídia, como símbolos de um ambiente preservado, higienizado, idealizado e externo ao homem. A microbacia real com os cursos d'água desaparece. É um ambiente generalista e descontextualizado, marca da escola na formulação de seus conceitos, ou seja, a generalidade sem história. Na Figura 2, o contato e aprendizado de um ambiente real, complexo e conflituoso: o igarapé poluído no bairro modificou o conceito de ambiente do aluno e o papel do igarapé em seu bairro e cidade. O contexto de aprendizagem está presente e marca os conceitos da professora e seus alunos. Essa diferença foi conseguida devido ao contato do aluno com um contexto real de aprendizado, colocando a possibilidade de conhecer o espaço e história do ambiente no qual vive e do entorno. No Brasil, esse ambiente real parece ser extirpado da escola. Os motivos são muitos, mas um muito evidente é o de arrefecer a capacidade de conhecer criticamente os problemas reais, o que possibilitaria que os alunos se sentissem pertencentes ao local, ao bairro e à comunidade e pudessem participar da resolução dos problemas que os envolvem.

\section{B) Zona de desenvolvimento proximal e a prática docente}

Durante os estudos da relação entre desenvolvimento e aprendizado, Vygotsky (2000a) formulou o conceito de zona de desenvolvimento proximal, a qual, segundo ele, seria delimitada pela diferença estabelecida entre as tarefas que a criança consegue realizar de forma independente e aquelas que só podem ser executadas com o auxílio de adultos ou de outras crianças. 


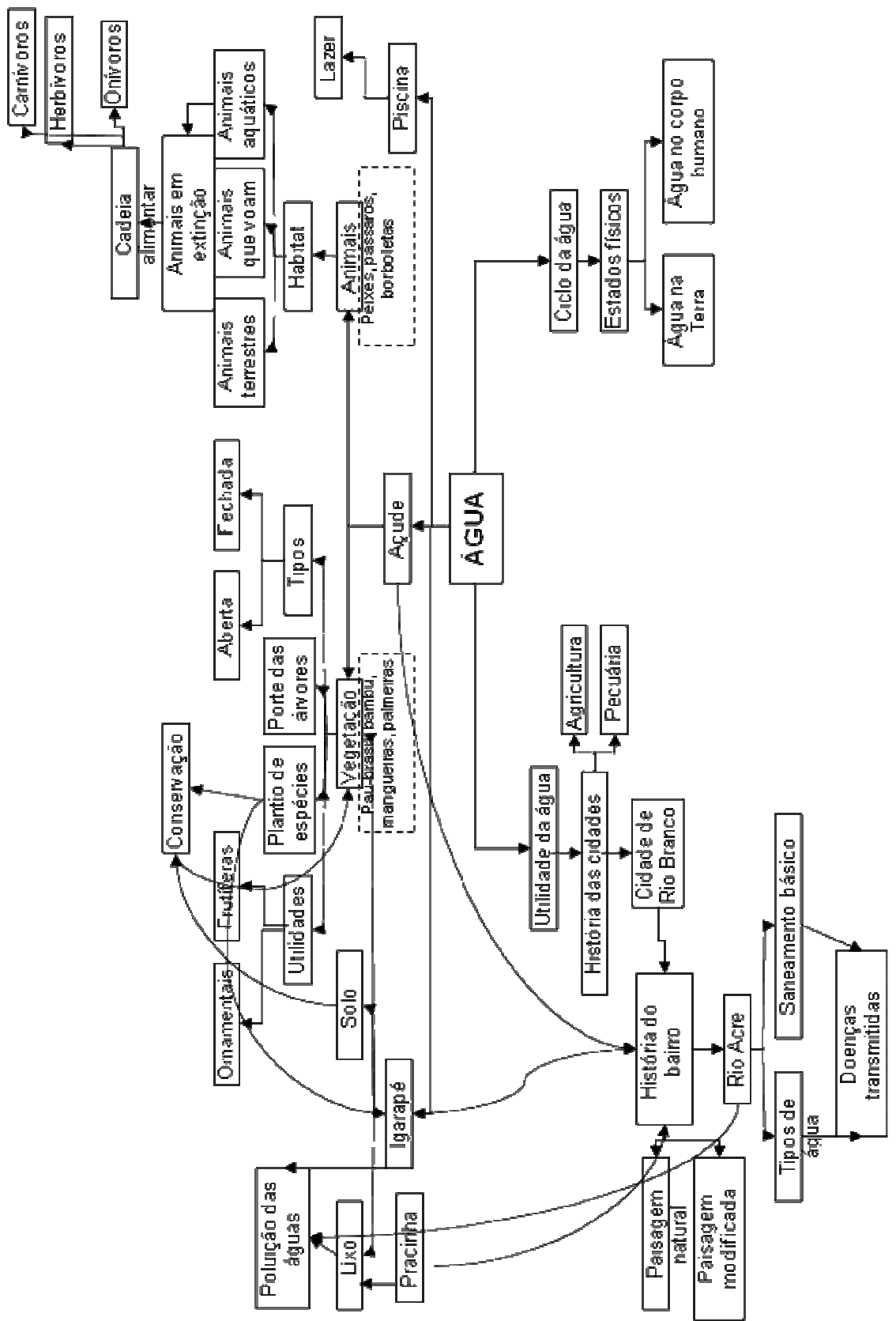

Figura 2. Mapa conceitual elaborado pela professora P1 após término da aplicação da unidade didática. 
Ao descrever a zona de desenvolvimento proximal, o autor afirma que ela define os "brotos" do conhecimento, fazendo uma analogia às funções psicológicas que estão presentes no indivíduo, mas ainda em fase de maturação. Nesse aspecto, se contrapõe à ideia implícita nos testes de Q.I. (Quociente de Inteligência), que verificam somente as funções que completaram seu processo de "amadurecimento", os chamados "frutos" do conhecimento.

Entendemos que o desenvolvimento real representaria os resultados de ontem e o desenvolvimento potencial seria característico de desempenho futuro, revelando os resultados de amanhã, portanto, o desenvolvimento potencial cartografado a partir do mapeamento da zona de desenvolvimento proximal poderia trazer implicações positivas se empregado no processo de aprendizado dos alunos. Vygotsky ainda acrescenta:

[...] a zona de desenvolvimento proximal permite-nos delinear o futuro imediato da criança e seu estado dinâmico de desenvolvimento, propiciando o acesso não somente ao que já foi atingido através do desenvolvimento, como também àquilo que está em processo de maturação (2000a, p.113).

Essas ideias nos levam a refletir sobre a importância de um processo de ensino-aprendizado guiado pelos brotos do conhecimento para encorajar/incentivar a maturação das funções psicológicas em desenvolvimento, ou um processo de aprendizado que se adiante ao desenvolvimento.

Outro aspecto importante que emerge da discussão das ideias vygotskyanas a respeito da zona de desenvolvimento proximal é o papel essencial do outro social para o desenvolvimento cognitivo e o quanto a escola propicia e potencializa esse contato.

Acreditamos que os processos de colaboração e cooperação, tais como os trabalhos em equipe, são essenciais para que as funções mentais amadureçam. A partir dessa perspectiva, Vygotsky assinala: 
(...) um aspecto essencial do aprendizado é o fato de ele criar a zona de desenvolvimento proximal; ou seja, o aprendizado desperta vários processos internos de desenvolvimento, que são capazes de operar somente quando a criança interage com pessoas em seu ambiente e quando em cooperação com os seus companheiros (2000a, p. 117).

É impossível discutir desenvolvimento e aprendizado sem tratar o processo de escolarização, uma vez que "o principal papel da escolarização é criar contextos sociais (zona de desenvolvimento proximal) para o domínio e manejo consciente dos usos dos instrumentos culturais” (MOLL, 1996, p. 13).

Para tanto, o autor alerta que as atividades desenvolvidas em sala de aula precisam estar socialmente inseridas no cotidiano da criança, ou seja, integradas às condições gerais de aprendizagem. Assim, pelo fato de morarem no Acre, a floresta faz parte do cotidiano desses alunos e está presente nos casos contados pelos parentes mais velhos que vieram do seringal ou nos produtos florestais consumidos por esses alunos, como o açaí, por exemplo. O fato é que, embora vivam em uma cidade, como no caso dos alunos das escolas de Rio Branco, as cidades amazônicas apresentam especificidades decorrentes da proximidade com a floresta.

Configura-se, assim, uma prática docente comprometida com os conhecimentos, valores e curiosidades dos alunos sobre os temas abordados em sala de aula, o que pode resultar, por exemplo, na realização de levantamentos das ideias dos alunos sobre a conservação da floresta ou do uso da água na cidade onde vivem. Nesse caso, é importante destacar a importância da inserção dos conhecimentos cotidianos dos alunos na construção do conhecimento realizado e indicado no processo de formação dos professores, levando-se em conta que "o ponto de partida dessa discussão é o fato de que o desenvolvimento da criança começa muito antes de elas frequentarem a escola. Qualquer situação de aprendizado na qual a criança se envolva na escola tem sempre uma história prévia" (VYGOTSKY, 2000a, p. 110). 
No Projeto Acre 2000 de EA, o levantamento de ideias sobre a temática ambiental aparece como condição para se construir o itinerário curricular. Em vez de simplesmente reproduzirem a proposta curricular da Secretaria de Educação, os professores envolvidos no projeto exercitaram sua autonomia construindo seus próprios itinerários em sala de aula, na busca de um novo ordenamento curricular.

Assim, ao analisarmos comparativamente as figuras 1 e 2, podemos afirmar que na Fig.1 predomina a voz do professor que veicula a forma como é comumente tratado o tema "água" nas escolas, forma essa ancorada nas generalizações e que não estabelece ligações com o contexto local, por exemplo, ao indicar os conteúdos: recurso natural, tipos de água, utilidade, distribuição, entre outros. Além disso, a nosso ver, a Fig.1 também expressa uma visão bastante fragmentada, uma vez que propõe o tratamento do tema "água" de modo isolado. Um exemplo disso seria o fato de não abordar as relações desse tema com a fauna e a flora. Aliás, ao observamos a figura, constatamos que só há uma menção implícita à fauna e à flora, e ela aparece, de modo bastante generalizado, no conteúdo "utilidade", ao indicar o trabalho com "seres vivos". Esse tratamento, pautado pelas generalizações e pela fragmentação, reforça uma concepção de educação ambiental bastante linear, na qual água se relaciona somente com o uso que o homem faz dela, representado na Fig. 1 por termos como "gasto" e "purificação"; ou com a relação de "preservação" ou "desperdício" que o mesmo estabelece com a água enquanto recurso "insubstituível", "essencial" e "esgotável". Ou seja, não é à toa que a "postura do homem diante da natureza" está no centro da figura.

$\mathrm{Na}$ Fig. 2, é possível perceber a voz dos alunos, que dialoga com a voz da professora e também com algumas vozes presentes na comunidade, como a do antigo morador do bairro onde se localiza a escola e que foi convidado a participar de uma aula, contando como era o bairro na época em que era menino. Assim, nessa mapa conceitual, a "história do bairro" aparece em destaque pelo fato de servir como elo para o tratamento de diferentes temas, tais como: "paisagem natural" e "paisagem modificada", "saneamento básico", "história das cidades", entre outros. A professora destaca a voz dos alunos ao inserir o tema "piscina", que a priori não fazia parte do 
trabalho planejado e passou a ganhar importância a partir do trabalho de campo com os alunos.

O mapa conceitual da Fig. 2 mostra a riqueza desse processo, fortemente marcada pelo aumento de interação dos conceitos, a possibilidade de uma compreensão menos fragmentada pelos alunos e professor. As interações dos alunos uns com os outros e com o professor foram constitutivas dessa complexidade de relações conceituais e cognitivas. A diferença é marcante entre a Fig. 1 e a Fig.2., e não poderia deixar de ser, pois se multiplicaram os diálogos e as interações de toda a zona de desenvolvimento proximal da classe, que é antes de qualquer coisa uma zona social de relações, conceituações e cognições. Assim, na Fig. 2 se expressa, a nosso ver, o exercício da professora em ir conduzindo os sentidos mais integradores, normalmente tratados fragmentadamente entre várias disciplinas.

A esse respeito, a entrevista da professora $\mathrm{P} 1$, cedida durante pesquisa de mestrado citada anteriormente, nos ajuda a compreender o papel do professor na mediação dos diálogos que vão constituindo os diversos sentidos produzidos pelos alunos em uma complexa zona social de sentidos e desenvolvimentos cognitivos:

P1 - "Eu queria despertar a curiosidade deles, despertar para quando fôssemos para a sala para aplicar a unidade. Eles já teriam uma ideia, teriam algo para falar, através das perguntas que tínhamos feito e das respostas. Ali no campo, era aguçar, tipo um diagnóstico para saber o que eles achavam das coisas, o que eles sabiam. Por exemplo, quando fomos olhar o igarapé, eles perguntaram se era o mesmo que passava perto da casa deles e eu disse que era. Perguntei: Por que será que aqui ele está de um jeito e lá, de outro', ou seja, é o comparar as realidades. Ai em sala tinha que deixá-los mais à vontade para falar. [...] o meu objetivo era em cima do tema água, o meu objetivo era tratar da água mesmo, os problemas, os pontos positivos, negativos. Eu queria mais assim: eu queria que eles despertassem para uma coisa a que eles não estavam atentos, até que eles poderiam saber, como eles sabiam muita coisa e sabem, mas ficarem mais atentos aos problemas, muita coisa admirou eles. Se você perguntar o que a gente deve fazer com o meio ambiente, eles sabem, mas eu queria aprofundar mais." 
Foi a partir da atenção dada pela professora para ouvir seus alunos que se tornou possível a articulação entre as observações, questionamentos, sentimentos e falas durante o trabalho de campo e as demais atividades desenvolvidas posteriormente em sala de aula, mantendo-se assim o foco organizativo da unidade didática no contexto local.

\section{C) Construção de conceitos à luz da mediação dialógica}

Neste aspecto discutiremos a importância da mediação do professor no processo coletivo de construção de conhecimento. Nesse sentido, destacamos a necessidade de o professor considerar também os conhecimentos cotidianos durante a mediação dialógica em sala de aula, promovendo uma "conversa" entre as noções, situações e valores que permeiam a vida cotidiana do aluno e os conhecimentos científicos necessários ao entendimento de complexos problemas e fenômenos ambientais locais. Caso contrário, aos alunos só restaria decorar as palavras do professor e expô-las, quando fossem solicitados nos testes e provas, para dizer aquilo que o professor quer ouvir. Afirmamos isso porque concordamos com Vygotsky quando este afirma que:

A experiência prática mostra que o ensino direto de conceitos é impossível e infrutífero. Um professor que tenta fazer isso geralmente não obtém qualquer resultado, exceto o verbalismo vazio, uma repetição de palavras pela criança, semelhante à de um papagaio, que simula um conhecimento dos conceitos correspondentes, mas que na realidade oculta um vácuo (VYGOTSKY, 2000b, p. 104).

Além disso, em se tratando de uma temática que permeia vários discursos em nossa sociedade, dos quais emanam diferentes ideias, é fundamental que os professores envolvidos com a inserção da educação ambiental nos itinerários escolares adotem o papel de intérpretes da realidade, mediando as interações sociais em sala de aula e nos trabalhos de campo, bem como as interações dos conhecimentos cotidianos com os científicos, para possibilitar uma desconstrução de 
discursos fechados e estereotipados (ORLANDI, 1996) sobre a problemática ambiental. É fundamental a reconstrução de conceitos que não apenas dialoguem com as ideias, crenças e valores dos alunos mas também possam evidenciar uma visão de mundo mais complexa.

Consideramos a transmissão do conhecimento infrutífera, uma vez que a criança, quando lê ou ouve uma palavra que não conhece inserida numa frase compreensível, tem uma vaga ideia desse conceito novo, porém, com o tempo sentirá necessidade de usar essa frase, dando início ao processo de apropriação do conceito (VYGOTSKY, 2000b, p. 105).

As ideias de Candela somam-se às expostas anteriormente quando a autora considera que as situações de interação, bem como as histórias e características individuais, participam da construção das várias versões de um mesmo conteúdo. E acrescenta: "Estas versões são confrontadas, negociadas e reconstruídas no próprio processo da interação, e é nesse processo interativo que vão sendo definidos os diversos significados" (CANDELA, 1998, p. 144) A Fig. 2 é de novo um exemplo da riqueza de negociações de conceituações realizadas pela professora e seus alunos.

Nesse sentido, os processos de ensino-aprendizagem desenvolvidos no âmbito do Projeto Acre 2000 privilegiaram o encontro das vozes dos participantes durante os trabalhos de campo e os encontros formativos. Ao serem ouvidas pelos formadores e perceberem que as suas ideias eram consideradas e permeavam o processo, as multiplicadoras puderam vivenciar a construção do conhecimento segundo os princípios socioconstrutivistas, que foram posteriormente sistematizados e estudados durante o curso sobre socioconstrutivismo e práticas em educação ambiental, vinculado ao projeto.

A relevância do desenvolvimento da habilidade social de ouvir, fortemente trabalhada pelos formadores e posteriormente pelas multiplicadoras, à luz das ideias de Bakhtin, decorre do fato de pensarmos que a compreensão é dialógica por natureza e que propomos um conjunto de palavras nossas como respostas para cada palavra do enunciado que estamos em processo de compreender (BAKHTIN, 2002). 
Essa percepção aponta uma ideia de significado mais dinâmica, pois considera que o emissor é influenciado por receptores passados e futuros, num processo de criação de significados. A voz do destinatário também está envolvida na cadeia da comunicação verbal, mas a voz do falante pode indicar uma consciência dela e refleti-la na produção dos enunciados (WERTSCH, 1993).

Segundo defende Bakhtin (2002), o enunciado reflete não somente a voz que o produz mas também as vozes a que se dirige. Isso ocorre porque, durante a formulação do enunciado, a pessoa que está falando leva em consideração aquilo que acredita que o ouvinte pensa sobre o assunto abordado e, por isso, o enunciado está associado a pelo menos duas vozes.

Acredita-se que em sala de aula se faz necessário que os alunos possam dialogar, colocando suas percepções de mundo e influenciando-se mutuamente durante o processo coletivo de construção de conceitos. Um exemplo disso são as aulas-debate, que caracterizam uma nova dinâmica na sala de aula, em que o professor não é o único que fala e expressa suas ideias e sentimentos, mas aquele que medeia os diferentes enunciados para a construção de um conhecimento mais atual.

Uma das professoras (P2), ao se referir às aulas-debate desenvolvidas com os alunos, aponta a importância da apreensão do conceito de zona de desenvolvimento proximal e do mapeamento da mesma enquanto elemento norteador da prática docente.

P2 - "Para desencadear a aula-debate com argumentações mais sólidas sobre um determinado aspecto do tema, antes eu fazia um novo levantamento de ideias prévias para descobrir a nova zona de desenvolvimento proximal em que se encontravam. Em seguida, selecionava poesias, lendas, reportagens, filmes, textos informativos e os trabalhávamos. Só então, após os minidebates sobre cada um desses, é que fazíamos a chamada grande aula-debate."

\section{Considerações}

Para a educação ambiental a importância do socioconstrutivismo está no fato de permitir que os envolvidos, 
durante as interações dialógicas ocorridas no processo formativo, percorram um processo de desconstrução e construção de conhecimentos/conceitos comumente utilizados no discurso ambientalista. Esses conceitos muitas vezes sofrem um esvaziamento de conteúdo ao permearem o discurso ambientalista divulgado em veículos de comunicação de massa, configurando-se em um discurso predominantemente fechado, caracterizado por termos estereotipados (chavões) que não permitem a interação dos interlocutores com aqueles que os produzem (ORLANDI, 1996).

Um exemplo desse discurso fechado, ou seja, que não considera os alunos enquanto interlocutores, é o tratamento dado inicialmente à "preservação", conforme aparece na Fig.1, o qual se configura pela generalização e a desvinculação do contexto em que os alunos vivem, bem como das especificidades sociais, econômicas, culturais e políticas do mesmo. Contudo, consideramos que nesse caso o problema não é a generalização em si, mas a generalização a priori; a "generalização pela generalização", enquanto concepção de conhecimento, que não carrega em si as especificidades do local como síntese espaço-tempo à qual os alunos pertencem.

Nossa hipótese é que a incorporação de trabalhos de campo e da linguagem visual no processo de ensino-aprendizagem poderia clarear e propiciar uma atitude crítica diante do uso corriqueiro, na escola, de recursos descontextualizados, que apresentam conceitos e generalizações (primado dos enunciados e fórmulas) sem conexões com os respectivos objetos e fenômenos singulares dos locais onde estão as escolas e vivem os alunos.

O uso de atividades de natureza pedagógica socioconstrutivista nos permitiu: i) acessar as ideias que os envolvidos no processo formativo apresentavam sobre as questões ambientais enfocadas; ii) estabelecer um processo dialógico entre os diversos conhecimentos / valores que os indivíduos possuíam sobre a questão e entre esses conhecimentos e aqueles produzidos pela ciência e iii) promover um fluxo entre esse processo dialógico externo (entre indivíduos e destes com leituras/textos/filmes etc.) e o diálogo interno, que ocorre em relação à estrutura cognitiva dos indivíduos. 
A realização do estudo do meio, dos trabalhos de campo e das aulas-debates situou a construção dos conhecimentos/conceitos numa perspectiva local/regional de observação e problematização da temática ambiental a fim de possibilitar a elaboração de uma visão de mundo mais complexa na qual se ancore a compreensão das questões ambientais.

\section{Referências}

BAKHTIN, Mikhail. Marxismo e filosofia da linguagem. 9. ed. São Paulo: Hucitec, Annablume, 2002. 196 p.

CANDELA, Antônia. A construção discursiva de contextos argumentativos no ensino de ciências. In: COLL, César; EDWARDS, Daniel (Org.). Ensino, aprendizagem e discurso em sala de aula. Porto Alegre: Artes Médicas, 1998. Cap. 6, p. 143-169.

COMPIANI, Maurício. Parceria entre Universidade e Escola Pública para a Formação Continuada de Professores do Ensino Fundamental com Temas de Geociências. In: ENCONTRO NACIONAL DE PESQUISA EM ENSINO DE CIÊNCIAS (ENPEC), 3., Atibaia - SP, 2001. Anais... Atibaia: ABRAPEC, 2001. CD-ROM.

Projeto Geociências e a Formação Continuada de Professores em Exercício no Ensino Fundamental: Reflexões e Resultados Finais. Zona Próxima, Colômbia, n. 3, p. 29-51, 2002.

COMPIANI et al. Projeto Geociências e a Formação Continuada de Professores em Exercício do Ensino Fundamental. 4 ${ }^{\circ}$ Relatório científico parcial, 1999. FINEP processo n. 63.96.0785.00.

COMPIANI, Maurício; FIGUEIRÔA, Silvia F.M.; NEWERLA, Vívian. Parceria Universidade e Escola Pública na Formação Continuada de Professores Desenvolvendo a Pesquisa do Professor. In: REUN. ANUAL DA ANPED, 25., Caxambu/MG, 2002. Anais... Caxambu: ANPEd, 2002. CD-ROM. 
COPELLO, Maria Inés. Fundamentos teóricos e metodológicos de pesquisas sobre ambientalização da escola. Pesquisa em Educação Ambiental, São Carlos, v. 1, n. 1, p. 93-110, 2006.

DIETZ, Lou Ann; TAMAIO, Irineu (Coord.). Aprenda Fazendo: apoio aos processos de Educação Ambiental. Brasília: WWF Brasil, 2000. 386 p.

GARCÍA, José Eduardo; CANO, Maria Isabel. ¿Cómo nos puede ayudar la perspectiva constructivista a construir conocimiento en educación ambiental? Revista Iberoamericana de Educación, n. 41, p. 117-131, 2006.

MOLL, Luis C. Vygotsky e a Educação. Porto Alegre: Artes Médicas, 1996.

ORLANDI, Eni Puccinelli. O Discurso da educação ambiental. In: TRAJBER, Rachel; MANZOCHI, Lúcia Helena (Org.). Avaliando a educação ambiental no Brasil: materiais impressos. São Paulo: Gaia, 1996.

PANZERI, Carla Gracioto. Educação Ambiental e itinerários curriculares no cotidiano das séries iniciais do ensino fundamental - contribuições teóricometodológicas do projeto Acre 2000 de Educação Ambiental, Rio Branco/AC. 2006. 127 p. Dissertação (Mestrado - IG-Universidade Estadual de Campinas, Campinas, 2006.

PANZERI, Carla Gracioto; COMPIANI, Maurício. O caminho da contextualização para o tratamento de temas sócio-ambientais nas séries iniciais do ensino fundamental. In: ENCONTRO NACIONAL DE PESQUISA EM ENSINO DE CIÊNCIAS (ENPEC), 4., 2003, Bauru-SP. Anais... Bauru: ABRAPEC, 2003. CD-ROM.

PANZERI, Carla Gracioto; COMPIANI, Maurício. O papel do estudo do meio na formação continuada de professores em educação ambiental: uma experiência desenvolvida na Amazônia Brasileira. In: SIMPÓSIO IBÉRICO DO ENSINO DA GEOLOGIA; SIMPOSIO SOBRE ENSEÑANZA DE LA GEOLOGÍA, 14., 2006, Aveiro. Livro de Actas. Aveiro: Tipave Ind. Gráfica, 2006. v. 1. p. 419-424. CD-ROM.

PANZERI, Carla Gracioto; REZENDE, Lindomar Soares; COMPIANI, Maurício; REIS, Vera Luúcia (Org.). Formação Continuada de Professores em Educação Ambiental: uma proposta metodológica. Rio Branco: PRINTAC, 2007. 106 p. (v. 1). 
PINO, Angel. A interação social: perspectiva sócio-histórica. In: ALVES, Maria Leila (Coord.). Construtivismo em revista. São Paulo: FDE, 1993. p. 49-58

SAUVÉ, Lucie. Uma cartografia das correntes em educação ambiental. Trad. Ernani Rosa. In: SATO, Michèle; CARVALHO, Isabel Cristina de Moura (Org.). Educação ambiental: pesquisa e desafios. Porto Alegre: Artmed, 2005. p. 17-44.

SCHÖN, Donald A. Formar professores como profissionais reflexivos. In: NÓVOA, António (Coord.). Os professores e sua formação. 2. ed. Lisboa: Dom Quixote, 1995.

SOS AMAZÔNIA; WWF-BRASIL. Relatórios Técnicos do Projeto Acre 2000 de EA. Rio Branco: 2000, 2001 e 2002.

VAN DER VEER, Rene; VALSINER, Jaan. Vygotsky: uma síntese. São Paulo: Loyola, 1996. 479 p.

VYGOTSKY, Lev S. A formação social da mente: O desenvolvimento dos processos psicológicos superiores. 6. ed. São Paulo: Martins Fontes, 2000a. $191 \mathrm{p}$.

Pensamento e linguagem. 2. ed. São Paulo: Martins Fontes, 2000b. 194 p.

WERTSCH, James. Más allá de Vygotsky: la contribución de Bajtín; La pluralidadd de voces del significado. In: . Voces de la Mente. Madrid: Visor, 1993. cap. 3, p. 65-86; cap. 4, p. 87-114. 